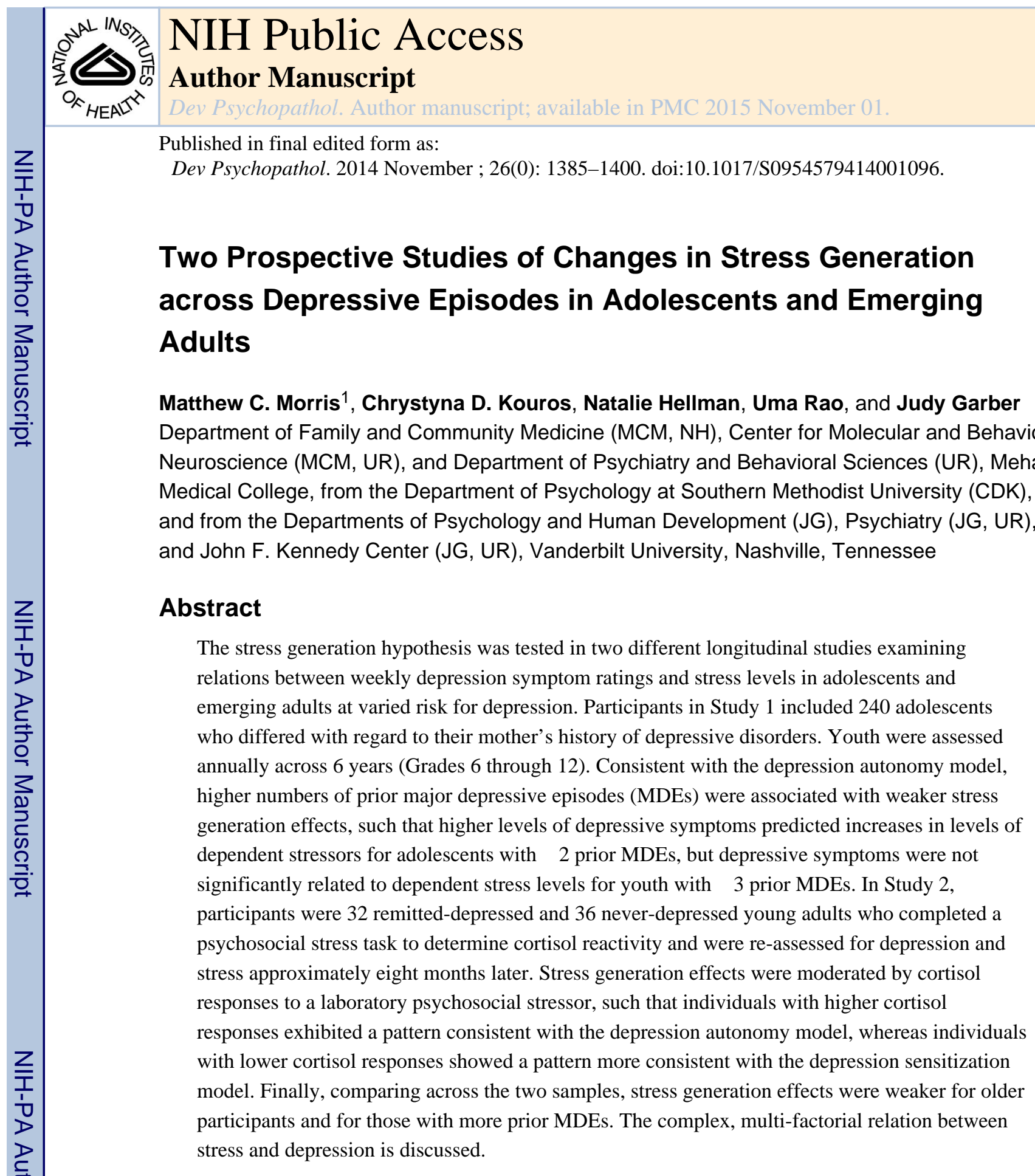

\title{
Keywords
}

depression; at-risk; stress; adolescents; emerging adults

\begin{abstract}
Stress has long been recognized as playing a central role in the development and course of depression across the lifespan (e.g., Grant, Compas, Thurm, McMahon, \& Gipson, 2004; Hammen, 2009; Kendler, Karkowski, \& Prescott, 1999; Monroe \& Harkness, 2011). This
\end{abstract}

\footnotetext{
${ }^{1}$ Corresponding Author Address: Matthew C. Morris, Ph.D., Meharry Medical College, 1005 Dr. D. B. Todd Jr. Boulevard, Nashville, TN 37208, Phone: (615) 327-6962, Fax: (615) 327-6144, mmorris@ mmc.edu.
} 
stress-depression relation is complex, bidirectional, and moderated by a range of factors including genes, physiology, neuroendocrine functioning, temperament, negative cognitions, and prior depressive episodes (e.g., Abramson, Metalsky, \& Alloy, 1989; Caspi et al., 2003; Monroe \& Harkness, 2011; Solomon et al., 2000). The purpose of the two studies reported here was to explore variability in the strength of the relation between depression and stress as a function of the number of prior depressive episodes (Studies 1 and 2) and cortisol reactivity (Study 2).

Several different models have been proposed to explain the link between stress and depression. Stress-exposure models emphasize that risk for depression increases following the experience of stressful life events (e.g., Abramson et al., 1989; Brown \& Harris, 1978). Stress sensitization models extend the stress-exposure model by proposing that the relation of stress to depression strengthens with each successive major depressive episode (MDE; for a review see Monroe \& Harkness, 2005), such that lower levels of stress become increasingly capable of triggering depressive symptoms as the number of prior MDEs increases. Identifying markers and mechanisms underlying recurrence is critical given that risk for depression increases with each additional MDE (American Psychiatric Association, 2000; Solomon et al., 2000).

Stress generation models complement traditional stress-exposure approaches by emphasizing the role of the individual as an active contributor to his/her environment. That is, individuals with current or past depression presumably possess certain characteristics or engage in behaviors that result in higher rates of dependent stressful events (e.g., relationship break-up), than independent or fateful life events (e.g., death of a relative), which are unrelated to their behavior (Brown \& Harris, 1978; Hammen, 1991). Stress generation processes have been implicated in risk for the recurrence of depressive episodes (Hammen, 2009). Less clear, however, is whether the relation of depression to dependent stressful events changes across successive MDEs in the manner described in stress sensitization models (Monroe \&Harkness, 2005).

The present report adopted a multilevel, developmental psychopathology approach (Cicchetti \& Toth, 2009) to investigating models of the relation between stress and major depressive disorder (MDD). We conducted two separate longitudinal studies to test withinindividual changes in the relation of stress and depression as a function of the number of prior MDEs experienced. Building upon existing stress generation models (e.g., Hammen, 2006) and using a multi-level of analysis approach, in Study 2, we investigated the interplay among hypothalamic-pituitary-adrenal (HPA) responses to acute psychosocial stress, prior MDEs, and weekly depression symptoms as predictors of dependent stress levels.

Support for stress generation models comes from studies of community samples of adolescents (e.g., Hammen \& Brennan, 2001; Patton, Coffey, Posterino, Carlin, \& Bowes, 2003) and adults (e.g., Cui \& Vaillant, 1997; Hammen \& Brennan, 2002; Harkness \& Luther, 2001), and clinical samples of children and adolescents (e.g., Rudolph \& Hammen, 1999; Rudolph et al., 2000) and adults (e.g., Chun, Cronkite, \& Moos, 2004; Hammen, 1991; Hammen, Davila, Brown, Ellicott, \& Gitlin, 1992; Harkness, Monroe, Simons, \& Thase, 1999). Prospective, multi-wave designs are required to adequately model change 
over time (Singer \& Willett, 2003) and have provided the strongest evidence of stress generation in depression. For example, depressive symptoms predicted major life events in two community samples of children and adolescents (Cole, Nolen-Hoeksema, Girgus, \& Paul, 2006), and predicted increases in romantic stressors in adolescents (Hankin, Mermelstein, \& Roesch, 2007). Increases in depressive symptoms also have predicted increases in dependent negative life events during the transition to adolescence (Johnson, Whisman, Corley, Hewitt, \& Rhee, 2012). Internalizing symptoms have been shown to predict increases in major life events (Kim, Conger, Elder, \& Lorenz, 2003) and higher levels of school-related hassles in adolescents (Carter, Garber, Ciesla, \& Cole, 2006). In adolescent girls, prior depression predicted increases in dependent stressors (Daley et al., 1997) and depressive symptoms predicted more interpersonal stressors (Davila, Hammen, Burge, Paley, \& Daley, 1995). Other studies similarly have found stress generation effects for girls but not boys (Ge, Lorenz, Conger, Elder, \& Simons, 1994; Rudolph, Flynn, Abaied, Groot, \& Thompson, 2009).

Few multi-wave studies of stress generation have been conducted in young adults. In a large community sample followed from ages 15 to 30 years, depressive symptoms were found to predict major stressful events, although dependent and independent stressful events were not examined separately in this study (Pettit, Lewinsohn, Seeley, Roberts, \& Yaroslavsky, 2010). Among offspring of depressed mothers, depression predicted elevated interpersonal stress levels, in particular (Adrian \&Hammen, 1993). In a study of young adults, negative cognitive style, but not history of depression, predicted increases in both dependent and interpersonal stressors (Safford, Alloy, Abramson, \& Crossfield, 2007). Thus, some support for stress generation models has been found from multi-wave studies with children, adolescents, and young adults, although results have varied as a function of sample characteristics (e.g., sex), stressor types (e.g., major life events versus daily hassles), and index of depression (e.g., depression history versus symptoms).

Risk factors for depression onset or recurrence, including maternal depression and personal history of depression, may be relevant to stress generation processes. Maternal depression is linked to increased risk for depression in offspring (Beardslee, Glastone, \& O'Connor, 2012), high rates of stressful life events (e.g., Billings \& Moos, 1983), and strong associations between life stress and depressive symptoms (e.g., Langrock, Compas, Keller, Merchant, \& Copeland, 2002). Similarly, having had previous depressive episodes is linked to increased risk for depression recurrences (Keller et al., 1992) and strong associations between life stress and depressive symptoms (Monroe \& Harkness, 2005). Although some studies indicate that the rates of dependent events are higher among currently-depressed as compared to remitted-depressed individuals (e.g., Hammen, Mayol, deMayo, \& Marks, 1986), other studies have reported stress generation effects (i.e., dependent stressors) in remitted-depressed individuals as well (Daley et al., 1997; Hammen, 1991; Hammen \& Brennan, 2002; Kessler \& Magee, 1993). This latter finding in remitted-depressed individuals suggests that the characteristics and behaviors associated with dependent life events may be relatively enduring and not just state-like concomitants of being in a current MDE (Hammen, 2006). 
Similar mechanisms have been proposed to account for higher depression risk in offspring of depressed mothers and individuals with a history of depression, including dysfunctional neuroregulatory mechanisms and exposure to stressful environments (e.g., Goodman, 2007; Goodman \& Gotlib, 1999; Gotlib \& Joorman, 2010; Hammar \& Årdal, 2009; Monroe\& Harkness, 2005). The present studies used high-risk research designs, in which risk for depression was operationalized as either maternal depression (Study 1) or a personal history of depression (Study 2). Such over-sampling of high-risk individuals provides increased variability in the constructs of primary interest - dependent life events and depressive symptoms - and offers greater statistical power for detecting moderation effects.

Developmental factors also may be relevant to stress generation. For example, Cole and colleagues (2006) followed a large sample of children across 12 waves of data collection from grades 3 to 8 and found that stress generation effects strengthened with age. They speculated that this could reflect "children [becoming] more active agents in the construction of both positive and negative aspects of their environments" (p. 44). The current paper reports the results of two separate studies of stress generation using different aged samples - one with adolescents and the other with young adults. The period of emerging adulthood is particularly associated with increasing identity exploration, selfsufficiency, and challenging new role transitions (Arnett, 2000). These developmental epochs are well-suited for testing models of stress generation both because they are characterized by elevated risk for depression onset (Hankin et al., 1998; Sorenson, Rutter, \& Aneschensel, 1991) and they capture changes in agency over the environment and increased variability in the levels of dependent stressors experienced.

\section{Depression Sensitization and Autonomy}

According to the stress generation hypothesis, individuals' creation of life stressors contributes to the chronicity (Harkness et al., 1999) and recurrence (Hammen, 1991, 2006; Harkness, Lumley, \& Truss, 2008) of their depressions. Previous studies have shown that dependent stressors predict depression (e.g., Rudolph et al., 2009) and risk for depression increases with recurrences (Solomon et al., 2000). Taken together, these findings raise the possibility that stress generation processes strengthen over successive MDEs and could serve as a dynamic mechanism of risk. According to this depression sensitization model, also referred to as "progressive stress generation" (Hammen, 2006), an individual's tendency to create stress when depressed increases with each additional MDE experienced. One potential mechanism for depression sensitization is described by information processing models of depression, such that recurrent MDEs strengthen the neural networks that link dysphoric mood and negative cognitions or information processing patterns due to their repeated co-occurrence (Segal, Williams, Teasdale, \& Gemar, 1996). These more easilyactivated negative cognitions, in turn, may initiate or exacerbate dependent stress levels.

In contrast, it is possible that the relation of depression to stress may weaken with each additional MDE, such that stress generation becomes less common over recurrences. This is referred to as the depression autonomy model, which is in keeping with the nomenclature previously established for the kindling hypothesis (Monroe \& Harkness, 2005). One potential mechanism for depressive episodes becoming more autonomous from life events 
over time could be that depressed individuals increasingly withdraw from others because of repeated interpersonal rejection or social ostracism. Such social avoidance may reduce opportunities for generating interpersonal stressors in particular.

Support for the depression sensitization model was found in a cross-sectional study of depressed adult outpatients, such that those experiencing a recurrent depressive episode had higher rates of past-year dependent stressors than those in their first episode. These two groups did not differ, however, with regard to dependent stressors in the 3 months preceding their current episode (Harkness et al., 1999). Another large ( $n=2,858)$, two-wave study showed that more severe depressive symptoms at baseline were associated with higher rates of dependent stressors over follow-up for individuals with a history of depression; this relation was not significant for individuals without a history of depression, however (Maciejewski, Prigerson, \& Mazure, 2000). In contrast, evidence consistent with the depression autonomy perspective comes from a cross-sectional study of depressed adolescents in which the severity of interpersonal stressors increased following the onset of youths' first MDE, but the severity of interpersonal stressors did not change significantly after the onset of a recurrent MDE (Harkness et al., 2008).

\section{Biological Stress Responses and Stress Generation}

Disruptions of major stress response systems such as the HPA-axis are well-documented in currently depressed individuals (Holsboer, 2000) and include elevated basal cortisol activity (Lopez-Duran, Kovacs, \& George, 2009), higher cortisol awakening responses (Vreeburg et al., 2009), and impaired HPA negative feedback on the dexamethasone suppression test (Ribeiro, Tandon, Grunhaus, \& Greden, 1993) as compared to non-depressed individuals. Psychosocial stress protocols gauge endogenous activity of the entire HPA system, complementing pharmacologic/neuroendocrine challenges (Rao, Hammen, Ortiz, Chen, \& Poland, 2008). In normative samples, transient cortisol increases in response to acute stressors involving social evaluation are typical (Dickerson \& Kemeny, 2004) and may be adaptive (Cicchetti \& Rogosch, 2001; de Kloet, Oitzl, \& Joels, 1999; Oitzl, Champagne, van der Veen, \& de Kloet, 2010), whereas long-term patterns of cortisol hyperactivity or hypoactivity have been linked to negative health outcomes (McEwen, 1998; Raison \& Miller, 2003). Currently depressed adults tend to show delayed cortisol recovery compared to nondepressed individuals (Burke, Davis, Otte, \& Mohr, 2005), and depressed adolescents show elevated cortisol responses to psychosocial stressors (Rao et al., 2008).

Altered cortisol responses to stress tend to persist into remission from an MDE (Morris \& Rao, 2014) and increase risk for recurrence (e.g., Chopra, Segal, Buis, Kennedy, \& Levitan, 2008). Cortisol responses to psychosocial stress have been found to interact with depression history to predict more rapid increases in depressive symptoms (Morris, Rao, \& Garber, 2012). To our knowledge, however, the possibility that cortisol responses moderate stress generation effects has not been examined. Therefore, one aim of Study 2 was to explore the relation of depression to stress as a function of an important biological indicator of the stress response - cortisol. 


\section{The Present Studies}

The goals of the two longitudinal studies reported here were to examine temporal features of the depression-stress relation and to test depression sensitization and autonomy models using prospective, within-individual designs. These studies investigated the extent to which stress generation effects were linked to a history of depression and continued to operate during inter-episode intervals. First, we hypothesized that level of depressive symptoms [i.e., clinician-rated Depression Symptom Rating (DSR) scores] would predict increases in dependent stress levels in both adolescents (Study 1) and young adults (Study 2). Consistent with the stress generation model, we did not anticipate that depressive symptoms would predict increases in independent stress levels. Second, we hypothesized that the number of prior MDEs would moderate the relation of depressive symptoms to dependent stress levels, such that stress generation effects would strengthen with each successive episode in a manner consistent with the depression sensitization model. Finally, we explored whether an indicator of participants' biological response to a psychosocial stress task - cortisol—would interact with the number of prior depressive episodes and depressive symptom levels (i.e., DSRs) to predict the extent of dependent stressors experienced during the follow-up interval (Study 2).

\section{Study 1}

Method

Participants-Participants in Study 1 were 240 adolescents and their mothers. Children were first assessed when they were in 6th grade (mean age $=11.86$ years, $S D=0.57$ ). The sample of adolescents was $54.2 \%$ female, $82 \%$ Caucasian, $14.7 \%$ African-American, and $3.3 \%$ other (Hispanic, Asian, Native American, or mixed ethnic background). Families were predominantly lower-middle (e.g., nurse's aide, salesclerk) to middle class (e.g., store manager, teacher), with a mean socioeconomic status (SES) rating of $41.84(S D=13.25)$ (Hollinghead, 1975).

Procedure-Parents of 5th grade children from metropolitan public schools were invited to participate in a study about parents and children. A brief health history questionnaire comprised of 24 medical conditions (e.g., diabetes, heart disease, depression) and 34 medications (e.g., antidepressants, anxiolytics) was sent with a letter describing the study to over 3,500 families. Of the 1,495 mothers who responded, 587 who had endorsed either a history of depression, use of antidepressants, or no history of psychopathology were screened by telephone. The remaining families were excluded because the mother did not report depression or indicated other kinds of serious health problems (e.g., cancer, multiple sclerosis). Of the 587 families screened, 238 were excluded because they did not indicate sufficient symptoms to meet criteria for a depressive disorder (38\%), had other psychiatric disorders that did not also include a depressive disorder (19\%), the mother or the target child had a serious medical condition (14\%), the family was no longer interested (21\%), the target child was not going into $6^{\text {th }}$ grade $(6 \%)$, or the family had moved out of the area $(2 \%)$. The remaining 349 mothers who reported either a history of depression or no history of psychiatric problems were interviewed using the Structured Clinical Interview for DSM diagnoses (SCID; Spitzer et al., 1990). Based on the SCID, 149 families were excluded 
because the mother indicated a history of psychiatric disorders that did not also include a depressive disorder or reported a serious medical condition, or the child had a serious and/or chronic medical illness or a pervasive developmental disorder. Inter-rater reliability was calculated on a random subset of $25 \%$ of these SCID interviews. There was $94 \%$ agreement $(\mathrm{kappa}=.88)$ for diagnoses of depressive disorders. The final sample of 240 families consisted of 185 mothers (high-risk group) who had a history of some kind of mood disorder (147 MDD; 38 Dysthymia, Depression NOS, or Adjustment Disorder with Depressed Mood) and 55 mothers who were lifetime free of psychopathology (low-risk group).

Mothers and children completed a battery of questionnaires and were interviewed separately about the child's psychiatric history by a research assistant who was unaware of the mothers' psychiatric history. The present study reports the results of the baseline (Grade 6) and annual follow-up assessments of the adolescents through grade 12. An abbreviated data collection was conducted when participants were in Grade 10 due to a temporary lapse in funding. Only those measures relevant to the current study are described here.

\section{Measures}

Depressive symptoms and disorders-Prior stress generation research has operationalized "depression" as either a major depressive episode (e.g., Daley et al., 1997) or the level of depressive symptoms (Joiner, Wingate, Gencoz, \& Gencoz, 2005; Potthoff, Holahan, \& Joiner, 1995). In the current studies, we tested the stress-depression models with regard to changes in depression symptom rating (DSR) scores based on the Longitudinal Interval Follow-up Evaluation (LIFE; Keller et al., 1987). DSRs reflect a combination of the number of depressive symptoms and the extent of impairment, are scored using a six-point scale ranging from none or few symptoms to a full diagnosis of a depressive episode, and provide both a dimensional and categorical index of depression. Examining the relation of changes in DSRs to stress levels allowed us to analyze weekly fluctuations in depressive symptoms and stress generation processes and afforded greater variability than onset of depressive episodes alone.

To assess adolescents' current and lifetime history of depression, mothers and adolescents were interviewed with the Schedule for Affective Disorders and Schizophrenia for SchoolAged Children-Present and Lifetime Version (K-SADS-PL; Kaufman et al., 1997) at the first evaluation. The LIFE (Keller et al., 1987), which assesses disorders since the previous interview, was conducted annually through grade 12 . As noted above, the LIFE yields a DSR score from 1 to 6 reflecting the extent of depressive symptoms and impairment for each week during the time interval examined. All interviews were audio-taped. A second rater who was unaware of the ratings of the primary interviewer reviewed a random $25 \%$ of the audiotapes. Inter-rater reliability for depression yielded a kappa of 0.81 .

Life events-Prior stress generation research has operationalized 'stress' as either the presence or absence of a severe life event (e.g., Harkness et al., 1999), the total number of stressful life events (e.g., Hankin et al., 2005), or cumulative event threat (e.g., Daley et al., 1997; Hammen, 1991; Shih, 2006). Similar to the cumulative event threat approach, we examined weekly stress levels reflecting the total stress severity ratings summed across all 
ongoing negative life events. To distinguish stress generation effects (i.e., depression predicting subsequent stress levels) from stress continuity effects (i.e., stress predicting subsequent stress levels), we controlled for prior dependent stress levels.

Life events were assessed annually with the Life Events Interview for Adolescents (LEIA; Garber, Keiley, \& Martin, 2002), which is based on the Life Events and Difficulties Schedule (Brown \& Harris, 1978, 1989) and the Life Stress Interview developed by Hammen et al. (1987). Mothers and adolescents were interviewed separately regarding events that had occurred for the adolescent during each week of the evaluation interval. The LEIA is a semi-structured interview that allows for more precise dating of events and the assessment of objective consequences of events given the particular context in which the events occurred. In separate interviews, mothers and adolescents were asked to describe the context and details of the event, who was involved, when it occurred, and what changed for the adolescent as a result of the event. Events in the adolescent's life that were reported by either the youth or the mother were included (see Morris et al., 2010 for additional details).

Interviewers presented information about each adolescent's life events to a group of trained raters. Based on all information from both sources, the group then rated the event with regard to the degree of objective threat the event had for the adolescent, using a scale ranging from 1 (none) to 7(severe). Stress severity ratings during the interval were obtained from annual assessments; each weekly stress severity rating was created by summing across stress levels for all ongoing events reported for that week. We computed separate sums of stress severity ratings for independent -- 'fateful' events occurring independently of the participant's behavior (e.g., death of grandmother), and dependent events -- resulting at least in part from the participant's behavior (e.g., suspended from school for truancy). Raters were unaware of any information about the mothers' or adolescents' psychopathology. Interrater reliability of the objective stress ratings were obtained by having interviewers present the information about each event simultaneously to two different groups who then independently rated the event. Based on 202 events, agreement among raters was $89.6 \%$ $($ kappa $=.79)$.

\section{Data Analytic Plan}

Most studies examining stress generation have used a fixed risk period approach in which the rates of dependent life events during a predetermined time period either before (e.g., Harkness et al., 1999) or after an MDE (e.g., Maciejewski et al., 2000) are compared for individuals with or without a history of depression. Previous studies have compared rates of dependent events during 3- and 12-month risk periods preceding MDE onset for recurrent versus first episode depressed individuals (Harkness et al., 1999) or have examined changes in rates of dependent events from a 3-month risk period preceding MDE onset to a 3-month risk period following MDE onset (Harkness et al., 2008). An alternative approach is to consider the timing of stress generation processes as an empirical question and to examine how it unfolds over time. Although some studies have investigated stress generation using multilevel modeling (MLM) and lagged depressive symptoms by one wave of data collection, which ranged from a few months to a year (e.g., Hankin, Stone, \& Wright, 2010), studies assessing stress generation processes have not yet applied lagged effects models to 
determine the lag at which depression has its strongest relation to dependent stressors. This latter approach was used in the current studies.

Specifically, to examine whether and to what extent weekly depressive symptom ratings (DSRs) were associated with subsequent weekly stress levels (dependent, independent), we tested a series of lagged effects models in which stress scores at time $t$ were predicted by lagged DSRs, controlling for stress levels using the same lag period, $n$ weeks prior. This approach treats the timing of stress generation effects as an empirical question in contrast to approaches that determine lag intervals a priori or based on the timing of assessments. These models were used here to identify the lag interval for which the beta coefficient representing the predictive relation of weekly DSRs to weekly dependent stress levels was largest; this lag interval then was used in subsequent models testing whether prior MDEs moderated stress generation effects. We anticipated that stress generation effects would be stronger for shorter lag intervals between DSRs and dependent stress levels and would diminish as lag intervals increased. In an effort to minimize the Type 1 error rate, we chose to continue examining larger lag intervals until stress generation effects were no longer significant, and to only interpret those that were significant at an alpha of .01.

To address the hypotheses regarding within- and between-individual change simultaneously, we specified a series of multilevel models using HLM 6 (Raudenbush, Bryk, \& Congdon, 2004) consisting of a within-person (Level-1) model describing how each individual changed over time and a between-person (Level-2) model describing how these changes varied across individuals (see Bryk \& Raudenbush, 1992; Singer \& Willett, 2003). All Level-1 predictors were person-centered (i.e., the means of these variables equaled zero for each person) and person means for time-varying predictors were included in Level-2 models in order to remove between-person variance from within-person variables and prevent predictors from correlating with individual intercepts or between-person factors (Hoffman \& Stawski, 2009).We next examined whether associations between DSRs and subsequent stress levels were moderated by the number of previous MDEs each participant had experienced up until that particular week. All models controlled for stress levels concurrent with DSRs, person means for depressive symptom ratings and stress levels, sex, SES, risk (i.e., maternal history of depression) and time. Variables included in interactions were centered. Simple slope analyses were conducted on all significant interactions, per Aiken and West (1991).

Level 1 model:

$$
\begin{aligned}
& \text { Stress }_{t i}=\pi_{0}+\pi_{1}(\text { Week })_{t i}+\pi_{2}(D S R)_{(t-n) i} \\
& \quad+\pi_{3}{\text { (Stress })_{(t-n) i}} \\
& \quad+\pi_{4}(\text { prior } M D E s)_{(t-n) i} \\
& \quad+\pi_{5}(\text { prior } M D E s \times D S R)_{(t-n) i}+\mathrm{e}
\end{aligned}
$$

Level 2 model: 


$$
\begin{gathered}
\pi_{0}=\beta_{00}+\beta_{01}(D S R \text { mean })+\beta_{02}(\text { Stress mean })+\beta_{03}(\text { Sex })+\beta_{04}(S E S)+\beta_{05}(\text { Risk })+r_{0} \\
\pi_{1}=\beta_{10}+r_{1} \\
\pi_{2}=\beta_{20} \\
\pi_{3}=\beta_{30} \\
\pi_{4}=\beta_{40} \\
\pi_{5}=\beta_{50}
\end{gathered}
$$

In this equation, the term 'Stress' denotes the individual's total level of dependent stress; 'Week' denotes the number of weeks from baseline (week 0) at time $t$ (maximum weeks $=$ 360 over the course of the study); DSR denotes the individual's depressive symptoms rating score; prior MDEs denotes the individual's cumulative number of MDEs experienced at each week during the study period, and DSR mean and Stress mean denote the individual's person-means for DSR scores and dependent stress levels (grand-mean centered), respectively. Thus, Stress $t i$ indicates the total dependent stress level at time $t$ for person $i$. Terms with subscript $(t-n)$ were the lagged effects of the $n^{\text {th }}$ week prior to Stress $t i$.

\section{Missing Data}

Data were available across study waves as follows: 226 participants completed all study measures for the interval between Grades 6 and 7, 224 for the interval between Grades 7 and 8, 217 for the interval between Grades 8 and 9, 206 for the interval between Grades 9 and 11 (a two-year interval was required due to the abbreviated data collection at Grade 10), and 197 for the interval between Grades 11 and 12. MLM analyses allowed for variability in the number of assessments for each participant. All available data for each participant were used. Participants with missing data at any time point $(n=43)$ did not differ significantly from participants with complete data $(n=197)$ on sex, $\chi^{2}(1)=3.20, p=.07$, maternal history of depression, $\chi^{2}(1)=3.78, p=.052$, number of total MDEs during the course of the study, $\chi^{2}(6)=4.52, p=.61$, or average dependent stress levels, $t(238)=1.46, p=.15$.

\section{Results and Discussion \\ Preliminary analyses}

Of the 240 adolescents in the initial sample, 230 were administered at least one stress assessment. For these participants, the mean number of weeks spent in this study was 275 
$(S D=67)$. Seven participants experienced one MDE before the baseline assessment. By the end of the study, 36 participants had experienced one MDE, 27 had experienced two MDEs, 5 had experienced three MDEs, 2 had experienced four MDEs, and one participant each experienced five, six, and seven total MDEs. Table 1 presents the means and standard deviations of all stress variables [dependent, independent, and total (dependent + independent)] for high-risk (i.e., history of maternal depression) and low-risk (i.e., no history of maternal depression) adolescents. A series of $t$ tests revealed that stress levels were significantly greater in high- as compared to low-risk youth.

\section{Is there a predictive relation between depressive symptom ratings (DSRs) and weekly dependent or independent stress levels?}

The specification of time-varying predictors, such as lagged effects, helps to clarify the temporal ordering of events. To test whether and to what extent DSRs predicted subsequent stress levels (i.e., forward relation), we ran a series of lagged effects models varying the lag interval $n$. Results indicated that the largest unstandardized beta for the relation between DSRs and dependent stress levels was at a lag of 6weeks; stress generation effects were significant up to a lag of 10 weeks (Figure 1). DSRs predicted decreases in independent stress levels from lag intervals of 8 to 10 weeks.

\section{Does depression history moderate the relation of depressive symptom ratings to weekly dependent stress levels?}

The interaction of number of prior MDEs and DSRs predicting dependent stress levels was significant $[b=-.04, t(59,209)=3.21, p=.002]$ (see Figure 2 and Table 2). Simple slope analyses indicated that higher DSRs significantly predicted higher levels of dependent stress for adolescents with no prior MDE $[b=.11, t(59,209)=6.35, p<.0001]$, one prior MDE $[b$ $=.08, t(59,209)=5.30, p<.0001]$, and two prior MDEs $[b=.04, t(59,209)=2.31, p=$. 021]. Depressive symptoms, however, were not significantly associated with dependent stress levels for individuals with three or more prior MDEs $[b=.01, t(59,209)=0.20, p=$. 838].

\section{Summary}

Consistent with our hypotheses, results from Study 1 indicated that depressive symptoms predicted increases in subsequent dependent stress levels. The relation of depressive symptoms to dependent stress levels peaked at a lag of 6 weeks. Elevations in depressive symptoms predicted decreases in independent stress levels occurring 8 to 10 weeks later. Contrary to expectations, stress generation effects diminished across successive MDEs in a manner consistent with the depression autonomy model.

\section{Study 2}

Although different in their original purposes, both Studies 1 and 2 share the goal of understanding risk for depression through the use of longitudinal, high-risk research designs. Each risk factor -- maternal depression (Study 1) and prior depressive episodes (Study 2) has been shown to be associated with a greater likelihood of the onset and recurrence of depression, respectively. Moreover, similar mechanisms have been proposed to account for 
this increased vulnerability (e.g., Goodman, 2007; Monroe \& Harkness, 2005). The purpose of Study 2 was to further examine stress generation processes in an independent sample of participants from an older developmental period, and to explore the acute cortisol responses to a laboratory-induced psychosocial stressor as another potential risk marker for stress generation. We hypothesized that individuals with higher cortisol responses and more prior MDEs would exhibit the strongest stress generation effects.

\section{Method}

Participants-Participants in Study 2 were 68 individuals, ages 18 to 31 years (mean age $=23.39, S D=3.88) ; 43$ were female $(63 \%)$ and their mean SES (Hollingshead, 1975) level was $54.05(S D=12.10)$, indicating middle class. They were recruited primarily from undergraduate and graduate programs at a mid-size university in the southeastern United States. Of 32 participants with a depression history, 13 had experienced one prior MDE, 10 had had two episodes, and 9 had experienced three or more episodes; 36 participants had no prior history of depression. By the end of the follow-up (mean weeks $=35.16, S D=9.03$ ), 8 participants had experienced one MDE and 1 participant had experienced 2 MDEs; three of the new MDEs were first onsets. All participants were randomly assigned (blocked on depression history and sex) to either a social evaluation (high-stress) condition ( $n=34 ; 17$ remitted-depressed; 17 never-depressed) or a no-evaluation (low-stress) condition ( $n=34 ; 15$ remitted-depressed; 19 never-depressed) as part of a larger study of cortisol reactivity to a psychosocial stressor in remitted-depressed and never-depressed young adults (Morris, Rao, Wang, \& Garber, 2014).

Exclusion criteria based on the primary study goals were current MDE, lifetime bipolar or posttraumatic stress disorder (PTSD), and health conditions or medications known to affect stress response systems. Individuals who screened for either (a) a history of MDD but were not currently in a depressive episode (remitted-depressed), or (b) no current or prior history of MDD (never-depressed) were scheduled for the clinical assessment and laboratory tasks. Inclusion in the remitted-depressed group required a past diagnosis of MDD according to the Diagnostic and Statistical Manual of Mental Disorders, 4th Edition, text revision (DSM-IVTR; American Psychiatric Association, 2000) criteria as determined by the Structured Clinical Interview for DSM-IV Axis I Disorders (SCID-I; First et al., 1996). Full remission was defined as an absence of significant symptoms of depression for at least two months.

Procedures-Individuals meeting study criteria based on the telephone screen were invited to participate. Participants were instructed to not drink alcohol, smoke, use illegal drugs, engage in strenuous exercise, or visit the dentist within 24 hours prior to their appointment, and to refrain from drinking (except water), eating, or brushing their teeth one hour before the session. Participants were screened for these behaviors at the beginning of the laboratory assessment. All laboratory sessions were conducted in the afternoon/early evening (i.e., between 2:00 and 7:00 PM) to minimize the effects of diurnal variation in cortisol.

After participants provided informed consent, they were administered the SCID-I modules. They completed the BDI-II and sat quietly for 10 minutes. Following this rest period, 
participants provided the first cortisol sample (T0: baseline). Then they were informed about the laboratory tasks and they provided the second cortisol sample at the end of the 10-minute preparation period (T1: anticipatory stress). Participants then were escorted to another room and given their task assignment. Participants in the high-stress condition were informed that their performance would be judged by a panel of evaluators, whereas those in the low-stress condition were informed that they would perform the tasks while alone and unobserved. For all participants, the speech task preceded a mental arithmetic task. Participants provided the third (T2: mid-task) cortisol sample between the speech and arithmetic tasks and the fourth (T3: post-task) cortisol sample immediately following the arithmetic task. They then completed a demographics questionnaire, rested for 10 minutes, provided the fifth (T4: recovery 1) cortisol sample, rested another 10 minutes, and then provided the sixth (T5: recovery 2) and final, cortisol sample. At the end of the session, participants were fully debriefed regarding the nature of the experimental manipulation.

Participants were contacted approximately 8 months $(M=35.16$ weeks, $S D=9.03)$ after the baseline assessment and asked to complete a measure of life events (PES) and a phone interview to assess the timing of recent life events and the LIFE to determine the frequency and duration of depressive symptoms. Follow-up interviews were conducted by MCM and a trained research assistant. Compensation was $\$ 30$ or course credit for the baseline assessment and $\$ 10$ for the follow-up assessment.

\section{Baseline Measures}

Depression-The SCID-I was administered to assess current and lifetime diagnoses of a subset of Axis I disorders (i.e., MDD, bipolar disorder, PTSD). Detailed information on all previous depressive episodes was obtained to determine the number of prior MDEs experienced. All interviews were audio-taped and a random $20 \%$ were re-rated for reliability by an independent evaluator. Inter-rater reliability for history of depression yielded a kappa of 1.00 .

Psychosocial Stressor-A version of the Trier Social Stress Test (TSST; Kirschbaum et al., 1993), modified to include two experimental conditions manipulating the degree of social evaluation, was used to elicit cortisol response to the stressor. The task consisted of a 5-minute free-speech and a 5-minute mental arithmetic test administered sequentially either in a "high stress" social evaluation condition or in a "low stress" no evaluation condition. Similar to TSST procedures used by others (e.g., Gruenewald, Kemeny, Aziz, \& Fahey, 2004), participants in the high-stress condition were told that the examiner would be in the room and their performance would be audio- and videotaped and then evaluated and compared to other participants by a panel of judges. Participants randomized to the lowstress condition were informed that they would perform the tasks alone in the room and they would be not be observed or evaluated.

Cortisol-Salivary cortisol samples were collected using a saliva collection device (Salivette; Sarstedt Inc., Newton, NC). Cortisol levels were determined in duplicate using a commercially available enzyme immunoassay kit (Enzyme-Linked Immuno Sorbent Assay, 
ALPCO diagnostics, Salem, NH). The lower detection limit, or sensitivity, of this assay is $1.0 \mathrm{ng} / \mathrm{ml}$. Inter- and intra-assay coefficients of variation were $7.0 \%$ and $4.4 \%$, respectively.

\section{Follow-up Measures}

Depression-The LIFE (Keller et al., 1987) was used to assess depressive disorders during the follow-up interval. The LIFE yields a DSR score from 1 to 6 , reflecting the extent of depressive symptoms and impairment for each week of the follow-up interval. A score of 3 indicates fewer symptoms (e.g., two to three symptoms) than full DSM-IV-TR criteria with mild or moderate impairment, 4 indicates four symptoms with moderate to marked impairment, and a score of 5 or 6 indicates an MDE with significant impairment. Inter-rater reliability for DSR scores over follow-up was computed for $10 \%$ of participants, yielding an intra-class correlation coefficient of 1.00 .

Life events-The Perceived Events Scale (PES; Compas et al., 1987) was used to measure the number and severity of life events experienced by participants during the follow-up interval. Participants were contacted by study staff following completion of the PES online and were interviewed to determine the timing and duration of all reported life events (i.e., week of onset and offset). Total weekly stress scores were calculated by summing ratings for all negative events (rated -1 to -4 on desirability) occurring each week. Stressful life events on the PES were categorized as either dependent -- the participant likely contributed to the event, such as interpersonal disputes (e.g., an argument with a friend), or independent -- the participant likely did not contribute to event (e.g., illness in a relative). Separate total weekly stress level scores were calculated for dependent events and independent events. Stress level scores were multiplied by -1 so that higher scores indicated higher stress levels.

Data analytic plan-Data analyses were conducted using the same procedures as in Study 1, except that prior MDEs were assessed only at baseline and were included in multilevel models as a Level-2 variable. All variables were examined for distributional properties and cases were screened for univariate and multivariate outliers. Cortisol data were logtransformed to reduce skewness. Total cortisol response to the TSST was computed as the area under the curve with respect to ground (AUCg; Pruessner, Kirschbaum, Meinlschmid, \& Hellhammer, 2003). Based on prior work showing no significant differences in AUCg cortisol between high- and low-stress conditions (Morris et al., 2014), MLM analyses collapsed across stressor conditions but included stressor condition as a Level-2 covariate.

\section{Results and Discussion}

Preliminary analyses-History of depression was indexed by the number of prior MDEs as assessed at baseline. Mean total duration summed across all previous MDEs was 15.11 months $(S D=21.12)$. Total stress levels and dependent stress levels over the follow-up period were significantly greater in remitted-depressed compared to never-depressed individuals; remitted-depressed and never-depressed individuals did not differ significantly in independent stress levels (Table 1).

\section{What is the relation between depressive symptom ratings and weekly stress} levels?-Analyses indicated that the largest unstandardized beta coefficient for the relation 
between DSRs and total dependent stress levels occurred at a lag of four weeks. At this interval, DSRs, controlling for dependent stress levels for that week, predicted a subsequent increase in dependent stress levels by a magnitude of $0.47(p<.0001)$, whereas DSRs did not predict increases in independent stress levels at any lag interval. Although stress generation effects (i.e., lagged DSRs predicting increases in subsequent dependent stress levels) were only significant up to a lag of 5 weeks, results are presented in Figure 3 for lag intervals up to 10 weeks to facilitate comparison with Study 1. At lags of 8 to 10 weeks, DSRs significantly predicted decreases in dependent stress levels, controlling for dependent stress levels that same week. In addition, DSRs predicted decreases in independent stress levels, controlling for independent stress levels that week, at lags of 6 through 10 weeks.

Does depression history moderate the relation of depressive symptom ratings to weekly dependent stress levels?-The interaction between lagged DSRs and number of prior MDEs (at baseline) significantly predicted dependent stress levels $[b=-$. $22, t(2,090)=5.51, p<.0001]$ (see Table 2 ). Simple slope analyses revealed that higher depression symptom ratings predicted subsequent increases in dependent stress levels; this relation decreased with each additional MDE [no prior MDEs, $b=.74, t(2,090)=7.01, p<$. 0001 ; one prior MDE, $b=.69, t(2,090)=6.74, p<.0001$; two prior MDEs, $b=.63, t(2,090)$ $=6.38, p<.0001 ;$ and three prior MDEs, $b=.57, t(2,090)=5.93, p<.0001]$.

\section{Do cortisol responses to a psychosocial stressor moderate stress generation} effects?-The three-way interaction of cortisol responses, prior MDEs, and lagged DSRs predicting dependent stress levels was significant $[b=-5.46, t(2,075)=7.87, p<.0001]$ (Figure 4 and Table 2). In individuals with higher cortisol responses to the laboratory stress task, higher depression symptom rating scores predicted higher levels of dependent stress for never-depressed individuals; the relation between DSRs and dependent stress was weaker for individuals with more prior MDEs, eventually becoming negative for those with 3 prior MDEs (simple slopes: no prior MDEs: $b=2.90, t(2,075)=8.81, p<.0001$; one prior MDE: $b=1.29, t(2,075)=5.15, p<.0001$; two prior MDEs: $b=-0.32, t(2,075)=1.09, p=.276$; and three prior MDEs: $b=-1.93, t(2,075)=4.50, p<.0001)$. In contrast, for individuals with lower (or more 'blunted') cortisol responses to the stress task, the relation of level of depressive symptom ratings to dependent stress levels was negative for never-depressed individuals and was stronger for individuals with more prior MDEs [simple slopes: no prior MDEs: $b=-0.78, t(2,075)=2.56, p=.011$; one prior MDE: $b=0.16, t(2,075)=0.62, p=$. 533; two prior MDEs: $b=1.09, t(2,075)=4.15, p<.0001$; and three prior MDEs: $b=2.02$, $t(2,075)=6.09, p<.0001]$.

\section{Comparison of stress generation effects in adolescents and emerging adults}

-To compare stress generation effects across the two samples from different developmental periods (i.e., adolescents and young adults), we standardized the stress variables and re-ran the analyses. The relation between DSRs and subsequent stress was .03 ( $S E=.01, p<$. $0001)$ for the adolescent sample and $.09(S E=.02, p<.0001)$ for the young adults. To further examine age differences in stress generation, we combined the Study 1 and 2 datasets and tested a model in which age moderated the relation between DSRs and dependent stress levels. To address the concern that stress generation effects may differ for older participants 
due to their history of depression rather than their age per se, we also included prior MDEs as a potential moderator. Results revealed that both age and number of prior MDEs moderated the relation of DSRs to dependent stress levels, such that stress generation effects were weaker for older participants $[b=-.01, t(54,754)=4.10, p<.0001]$ and for those with more prior MDEs $[b=-.01, t(54,754)=2.87, p=.005]$.

Summary-Results of Study 2 indicate that higher levels of depressive symptoms predicted higher dependent, but not independent, stress levels. Further, the relation of depressive symptoms to subsequent dependent stress levels was strongest at a lag of four weeks. Surprisingly, elevations in depressive symptoms predicted decreases in independent stress levels occurring six to ten weeks afterwards as well as decreases in dependent stress levels occurring eight to ten weeks afterwards. The number of MDEs experienced by participants prior to the baseline assessment moderated the relation between depressive symptoms and subsequent dependent stress levels in a manner consistent with the depression autonomy model; that is, stress generation effects were weaker for individuals with more prior MDEs.

The strength and direction of these stress generation effects, however, were further moderated by cortisol responses to a psychosocial stressor. Individuals with higher cortisol responses exhibited a pattern consistent with the depression autonomy model, whereas individuals with lower cortisol responses exhibited a contrasting pattern that was consistent with the depression sensitization model. Comparisons across studies indicated weaker stress generation effects in older as compared to younger individuals and for those who had experienced more prior MDEs.

\section{General Discussion}

The current two studies tested alternative theoretical models of the relation between stress and depression, and used multiple methods (e.g., self-report, interviews, laboratory stressor) and multiple levels of analysis (e.g., physiological, subjective, clinical ratings) to assess the constructs of interest and the relations among them (Cicchetti \& Toth, 2009). Evidence consistent with the depression autonomy model was found in two different risk samples and using somewhat different assessment methods. The relations of depressive symptoms to dependent life stress levels diminished across successive depression recurrences. Stress generation effects were observed for young adults with up to three prior MDEs and for adolescents for up to two prior MDEs. Importantly, stress generation effects were observed during intervals between depressive episodes and also characterized adolescents and young adults with no prior history of a depressive episode, suggesting that even subclinical depressive symptoms may contribute to dependent stressors. Taken together, these two studies provide evidence that stress generation processes are problematic and warrant closer clinical attention particularly during the early course of depression.

Relations of depressive symptoms to dependent stress levels were stronger in adolescents (Study 1) compared to the young adults (Study 2), even after controlling for depression history. In a study of young adolescents similar in age to our adolescent sample, Cole and colleagues (2006) found that the stress generation effects strengthened with age, at least 
from childhood to adolescence. The current studies extended these findings to individuals at elevated risk for depression and revealed that the association between depression and dependent stressors was stronger in adolescents as compared to young adults. This finding is somewhat surprising given that opportunities to generate dependent life stress likely increase as young adults gain autonomy and agency and navigate difficult role transitions (Arnett, 2000). The results of the comparison between adolescents and young adults should be interpreted with caution, however, given that all participants were not from the same sample and somewhat different procedures and measures were used.

Hammen and colleagues (2011) proposed a broad application of the stress generation model that "involves selection into, or creation of, potentially demanding and negative contexts that have several features. They involve ongoing relationships with others and have certain performance requirements that may exceed the individual's personal and material resources; they are enduring; and they typically affect life on a daily basis" (Hammen et al., 2011, p. 354). In the current studies, both adolescents and young adults at high risk for depression experienced higher overall dependent stress levels as compared to their low-risk counterparts, although the relation of depressive symptoms to subsequent dependent stress levels was stronger in the adolescent sample. This age comparison should be interpreted with caution, however, given the differences between the two samples, intervals between assessments, and measures used. Nevertheless, stress generation effects may be especially problematic for adolescents, particularly those whose mothers have a history of depression, and thus should be carefully monitored by clinicians. Longitudinal studies with the same sample of adolescents transitioning into young adulthood are needed to further address this issue of changes in the depression to stress relation over time.

Higher rates of dependent, but not independent, events are generally found in depressed samples (Hammen, 2006). Adolescents in the present study who were at increased risk for depression also experienced higher average levels of independent stress compared to lowrisk adolescents. This finding is consistent with studies showing higher frequencies of both dependent and independent negative life events in youth with a range of psychiatric conditions (Sandberg, McGuinness, Hillary, \& Rutter, 1998), higher independent life event threat in depressed adolescents compared to non-depressed adolescents over a 12-month period (Harkness \& Stewart, 2009), and depressive symptoms predicting a greater number of independent negative life events 12 months later among adolescent girls (Kercher, Rapee, \& Schniering, 2009).

Why might at-risk youth experience increased stress from independent events (e.g., arguments between parents), for which they are not responsible? In the adolescent sample in Study 1 , risk was defined by mothers' history of depression. Maternal depression is known to be characterized by a range of stressors including disadvantaged environments (e.g., Sawyer et al., 2000), chaotic family circumstances, and marital distress (Goodman, 2007). Harkness and Stewart (2009) proposed that more indirect stress generation processes leading to elevated independent stress levels could be particularly germane to children and adolescents, "whose environmental contexts are more closely yoked to those of their family" (p. 285). Hammen (2006) similarly argued that "an array of situational characteristics, such as opportunities for satisfying work, income, health, and educational attainment affect the 
likelihood of exposure to stressful life events, both fateful (independent) and interpersonal (dependent) events" (p. 1072).

Although mean levels of independent stress were greater in high- than low-risk adolescents over the course of Study 1, analyses of within-individual relations between depressive symptoms and independent stress levels yielded a different pattern of results. Surprisingly, increases in depressive symptoms predicted decreases in independent stress levels for both adolescents and young adults. One possible explanation is that although individuals at risk for depression may find themselves in more disadvantaged contexts characterized by higher overall levels of independent stress than low-risk individuals, as their depressive symptoms increase these at-risk individuals may withdraw from these environments and thereby reduce opportunities for exposure to certain independent life events. This withdrawal could be driven by anhedonia, motivational deficits, or disengagement coping strategies (Compas, Connor-Smith, Saltzman, Thomsen, \& Wadsworth, 2001). For example, disengaging from social contacts may reduce exposure to risky peer behaviors. Although withdrawal may prolong depression by reducing opportunities for positive reinforcement, it also may lessen exposure to stressful life events or to more dysfunctional social environments (Jacobson, Martell, \& Dimidjian, 2001). Stress sensitization and depression autonomy models may be interdependent. That is, as individuals grow more sensitive to stressors with each recurrent episode of depression, they also may alter their behaviors, which then may result in less exposure to such stressful life events.

Regarding the biological index of stress reactivity, cortisol responses to the laboratory stressor (i.e., TSST) moderated the stress generation effects in several interesting ways. Evidence consistent with the depression autonomy model was found for individuals with higher cortisol responses. In contrast, for those with lower cortisol responses the evidence was more in line with a depression sensitization model, and individuals were at greater risk for generating dependent stressors if they had experienced more prior MDEs. A recent review highlighted associations between stress-related psychopathology and both enhanced and diminished cortisol responses to the TSST (Allen, Kennedy, Cryan, Dinan, \& Clarke, 2014). Prior research generally has reported diminished cortisol responses in remitteddepressed individuals compared to never-depressed individuals (Ahrens, Deuschle, Krumm, van der Pompe, den Boer, \& Lederbogen, 2008; Bagley, Weaver, \& Buchanan, 2011; Brown, 2001; Chopra et al., 2008; Lange, Zschucke, Ising, Uhr, Bermpohl, \& Adli, 2013; Trestman et al., 1991). Longitudinal studies have shown that adolescents with lower cortisol reactivity to psychosocial stressors and higher stress levels across 12 months exhibited elevated depressive symptoms over the follow-up (Badanes, Watamura, \& Hankin, 2011).

Only two studies have examined HPA function as a predictor of subsequent stress levels. In a study of adolescents, elevated cortisol awakening responses (CAR) were found to predict MDEs for up to 2.5 years, but did not increase vulnerability to future major stressful life events (Vrshek-Schallhorn, Doane, Mineka, Zinbarg, Craske, \& Adam, 2013); this study did not assess the dependence versus independence of the life events, however. A second study of adolescents revealed that a combination of elevated evening cortisol secretion and persistent obsessive-compulsive disorder predicted greater occurrence of 'depressiondependent' life events (Goodyer, Park, \& Herbert, 2001). Findings from our Study 2 suggest 
that both elevated and diminished cortisol responses to a psychosocial stressor may represent risk markers for stress generation at different points in the course of depression. Future research testing depression prevention protocols (Adam, Sutton, Doane, \& Mineka, 2008) should consider including measures of HPA reactivity to the TSST in addition to measures of diurnal HPA activity (e.g., cortical awakening responses).

Some of the limitations of Study 2 were addressed by Study 1, including the use of an objective interview-based stress measure, a longer follow-up period allowing us to treat prior MDEs as a time-varying predictor, and a larger sample. Other limitations highlight directions for future research. For example, in the adolescent sample (Study 1), the assessments were conducted annually, whereas in the young adult sample the mean followup duration was 35 weeks. Although great care was taken to determine the dates of onset and offset of depressive symptoms and stressful events as precisely as possible using relevant anchor points (e.g., holidays, birthdays), reliance on retrospective reports may not have completely captured weekly fluctuations in stress generation processes. Future studies should include more proximal measures of stress such as daily diary methods or ecological momentary assessments (Shiffman, Stone, \& Hufford, 2008).

In addition, the present studies did not examine potential mechanisms contributing to change in dependent stress levels for at-risk individuals. An important next step will be to identify putative mediators of stress generation processes, including coping strategies, interpersonal relationships, social support, and cognitive vulnerability, using multi-wave longitudinal designs. Both interpersonal (e.g., reassurance-seeking) and cognitive (i.e., inferential style, self-criticism) vulnerability factors have been found to predict dependent interpersonal stressors above and beyond depressive symptoms (Shih, Abela, \& Starrs, 2009). Moreover, interpersonal processes such as neediness and co-rumination (e.g., Bouchard \& Shih, 2013) and social support (e.g., Davila, Bradbury, Cohan, \& Tochluk, 1997) may mediate the relation of depression to dependent interpersonal stressors. Prospective studies should examine whether changes in such vulnerability factors over time account for a weakening of stress generation effects across successive depression recurrences.

The findings of the current studies have several important clinical implications. First, adolescents and young adults appear to be at greater risk of generating stressful life events during their early MDEs as compared to later in the course of their depressions. Prevention and early intervention programs should target individuals with early-onset depression and help them recognize and alter their behaviors that contribute to increases in dependent life stressors. Preventing first onsets of depression is especially important given the recurrent and often debilitating nature of this disorder (Holsboer, 2000). Second, interventions should carefully assess how depressive symptoms may affect selection into problem environments, and also should assist at-risk youth in maximizing the experience of rewarding events and minimizing exposure to potentially stressful situations. Finally, assessing cortisol reactivity to psychosocial stressors in addition to recording their depression history may be informative about individuals' level of risk for generating dependent life stressors. 


\section{Acknowledgments}

Matthew C. Morris was supported in part by an American Psychological Foundation Elizabeth Munsterberg Koppitz Graduate Student Fellowship and grants from the National Institutes of Health (F31 MH084425, UL1 RR024975/TR000445, U54 RR026140/MD007593, G12 RR003032/MD007586, R01 MH068391, T32 MH018921, K01 MH101403). Chrystyna Kouros had been a fellow on training grant (T32 MH18921) from the National Institute of Mental Health. Natalie Hellman was supported in part by a grant from the National Institute of Health (G12 RR003032/MD007586). Uma Rao was supported in part by grants from the National Institutes of Health (R01 DA017805, R01 MH068391, G12 RR003032/MD007586, UL1 RR024975/UL1 TR000445 and U54 RR026140/MD007593) and by the Endowed Chair in Brain and Behavior Research at Meharry Medical College. Judy Garber was supported in part by National Institutes of Health grants R01MH64735, R01MH088329, and UL1 RR024975/UL1 TR000445 during the completion of this work. The content is solely the responsibility of the authors and does not necessarily represent the official views of the NIH.

\section{References}

Abramson LY, Metalsky GI, Alloy LB. Hopelessness depression: A theory-based subtype of depression. Psychological Review. 1989; 96:358-372.

Adam EK, Sutton JM, Doane LD, Mineka S. Incorporating hypothalamic-pituitary-adrenal axis measures into preventive interventions for adolescent depression: Are we there yet? Development and Psychopathology. 2008; 20:975-1001. [PubMed: 18606040]

Adrian C, Hammen C. Stress exposure and stress generation in children of depressed mothers. Journal of Consulting and Clinical Psychology. 1993; 61:354-359. [PubMed: 8473589]

Ahrens T, Deuschle M, Krumm B, van der Pompe G, den Boer JA, Lederbogen F. Pituitary-adrenal and sympathetic nervous system responses to stress in women remitted from recurrent major depression. Psychosomatic Medicine. 2008; 70:461-467. [PubMed: 18378864]

Aiken, LS.; West, SG. Multiple regression: Testing and interpreting interactions. Sage; Newbury Park, CA: 1991.

Allen AP, Kennedy PJ, Cryan JF, Dinan TG, Clarke G. Biological and psychological markers of stress in humans: Focus on the Trier Social Stress Test. Neuroscience and Biobehavioral Reviews. 2014; 38:94-124. [PubMed: 24239854]

American Psychiatric Association. Diagnostic and statistical manual of mental disorders. 4th ed.. Author; Washington, DC: 2000.

Arnett JJ. Emerging adulthood: A theory of development from the late teens through the twenties. American Psychologist. 2000; 55:469-480. [PubMed: 10842426]

Badanes LS, Watamura SE, Hankin BL. Hypocortisolism as a potential marker of allostatic load in children: Associations with family risk and internalizing disorders. Development and Psychopathology. 2011; 23:881-896. [PubMed: 21756439]

Bagley SL, Weaver TL, Buchanan TW. Sex differences in physiological and affective responses to stress in remitted depression. Physiology and Behavior. 2011; 104:180-186. [PubMed: 21396947]

Beardslee WR, Gladstone TRG, O'Connor EE. Developmental risk of depression: Experience matters. Child and Adolescent Psychiatric Clinics of North America. 2012; 21(2):261-278. [PubMed: 22537726]

Billings AG, Moos RH. Comparisons of children of depressed and nondepressed parents: A socialenvironmental perspective. Journal of Abnormal Child Psychology. 1983; 11:463-485. [PubMed: 6655148]

Bouchard LC, Shih JH. Gender differences in stress generation: Examination of interpersonal predictors. Journal of Social and Clinical Psychology. 2013; 32:424-445.

Brown, GW.; Harris, TO. Social origins of depression: A study of psychiatric disorder in women. Free Press; New York: 1978.

Brown, GW.; Harris, TO., editors. Life events and illness. Guilford; New York: 1989.

Brown, LL. Doctoral dissertation. Vol. 61. Vanderbilt University; 2001. The cortisol response to psychosocial stress in women at risk for depression; p. 6125BDissertation Abstracts International

Bryk, AS.; Raudenbush, SW. Hierarchical linear models. Applications and data analysis methods. Sage; Thousand Oaks: 1992. 
Burke HM, Davis SC, Otte C, Mohr DC. Depression and psychological response to stress: A metaanalysis. Psychoneuroendocrinology. 2005; 30:846-856. [PubMed: 15961250]

Carter JS, Garber J, Ciesla JA, Cole DA. Modeling relations between hassles and internalizing and externalizing symptoms in adolescents: A four-year prospective study. Journal of Abnormal Psychology. 2006; 115:428-442. [PubMed: 16866584]

Caspi A, Sugden K, Moffitt TE, Taylor A, Craig IW, Harrington H, McClay J, Mill J, Martin J, Braithwaite A, Poulton R. Influence of life stress on depression: Moderation by a polymorphism in the 5-HTT gene. Science. 2003; 301(5631):386-389. [PubMed: 12869766]

Chopra KK, Segal ZV, Buis T, Kennedy SH, Levitan RD. Investigating associations between cortisol and cognitive reactivity to sad mood provocation and the prediction of relapse in remitted major depression. Asian Journal of Psychiatry. 2008; 1:33-36. [PubMed: 23050993]

Chun CA, Cronkite RC, Moos RH. Stress generation in depressed patients and community controls. Journal of Social and Clinical Psychology. 2004; 23:390-412.

Cicchetti D, Toth SL. The past achievements and future promises of developmental psychopathology: The coming age of a discipline. Journal of Child Psychology and Psychiatry. 2009; 50:16-25. [PubMed: 19175810]

Cicchetti D, Rogosch FA. Diverse patterns of neuroendocrine activity in maltreated children. Development and Psychopathology. 2001; 13:677-693. [PubMed: 11523854]

Cole DA, Nolen-Hoeksema S, Girgus J, Paul G. Stress exposure and stress generation in child and adolescent depression: A latent trait-state-error approach to longitudinal analyses. Journal of Abnormal Psychology. 2006; 115:40-51. [PubMed: 16492094]

Compas BE, Connor-Smith JK, Saltzman H, Thomsen AH, Wadsworth ME. Coping with stress during childhood and adolescence: Problems, progress, and potential in theory and research. Psychological Bulletin. 2001; 127:87-127. [PubMed: 11271757]

Compas BE, Davis GE, Forsythe CJ, Wagner BM. Assessment of major and daily stressful events during adolescence: The adolescent perceived events scale. Journal of Consulting and Clinical Psychology. 1987; 55:534-541. [PubMed: 3624609]

Cui XJ, Vaillant GE. Does depression generate negative life events? Journal of Nervous and Mental Disease. 1997; 185:145-150. [PubMed: 9091595]

Daley SE, Hammen C, Burge D, Davila J, Paley B, Lindberg N, Herzberg DS. Predictors of the generation of episodic stress: A longitudinal study of late adolescent women. Journal of Abnormal Psychology. 1997; 106:251-259. [PubMed: 9131845]

Davila J, Bradbury TN, Cohan CL, Tochluk S. Marital functioning and depressive symptoms: Evidence for a stress generation model. Journal of Personality and Social Psychology. 1997; 73:849-861. [PubMed: 9325596]

Davila J, Hammen C, Burge D, Paley B, Daley SE. Poor interpersonal problem-solving as a mechanism of stress generation in depression among adolescent women. Journal of Abnormal Psychology. 1995; 104:592-600. [PubMed: 8530761]

de Kloet RE, Oitzl MS, Joels M. Stress and cognition: Are corticosteroids good or bad guys? Trends in Neurosciences. 1999; 22:422-426. [PubMed: 10481183]

Dickerson SS, Kemeny ME. Acute stressors and cortisol responses: A theoretical integration and synthesis of laboratory research. Psychological Bulletin. 2004; 130:355-391. [PubMed: 15122924]

First, MB.; Spitzer, RI.; Gibbon, M.; Williams, JB. User's guide for the Structured Clinical Interview for DSM-IV Axis I Disorders. New York State Psychiatric Institute, Biometrics Research Department; New York: 1996. research version

Garber J, Keiley MK, Martin NC. Developmental trajectories of adolescents' depressive symptoms: Predictors of change. Journal of Consulting and Clinical Psychology. 2002; 70:79-95. [PubMed: 11860059]

Ge XJ, Lorenz FO, Conger RD, Elder GH, Simons RL. Trajectories of stressful life events and depressive symptoms during adolescence. Developmental Psychology. 1994; 30:467-483.

Goodman SH. Depression in mothers. Annual Review of Clinical Psychology. 2007; 3:107-135.

Goodman SH, Gotlib IH. Risk for psychopathology in the children of depressed mothers: A developmental model for understanding mechanisms of transmission. Psychological Review. 1999; 106:458-490. [PubMed: 10467895] 
Goodyer IM, Park RJ, Herbert J. Psychosocial and endocrine features of chronic first-episode major depression in 8-16 year olds. Biological Psychiatry. 2001; 50:351-357. [PubMed: 11543738]

Gotlib IH, Joorman J. Cognition and depression: Current status and future directions. Annual Review of Clinical Psychology. 2010; 6:285-312.

Grant KE, Compas BE, Thurm AE, McMarhon SD, Gipson PY. Stressors and child and adolescent psychopathology: Measurement issues and prospective effects. Journal of Clinical Child and Adolescent Psychology. 2004; 23:412-425. [PubMed: 15136206]

Gruenewald TL, Kemeny ME, Aziz N, Fahey JL. Acute threat to the social self: Shame, social selfesteem, and cortisol activity. Psychosomatic Medicine. 2004; 66:915-924. [PubMed: 15564358]

Hammar $\AA$, Årdal G. Cognitive functioning in major depression: A summary. Frontiers in Human Neuroscience. 2009; 3:1-7. [PubMed: 19255629]

Hammen C. Generation of stress in the course of unipolar depression. Journal of Abnormal Psychology. 1991; 101:45-52. [PubMed: 1537972]

Hammen C. Stress generation in depression: Reflections on origins, research, and future directions. Journal of Clinical Psychology. 2006; 62:1065-1082. [PubMed: 16810666]

Hammen C. Adolescent depression: Stressful interpersonal contexts and risk for recurrence. Current Directions in Psychological Science. 2009; 18:200-204. [PubMed: 20161119]

Hammen C, Brennan PA. Depressed adolescents of depressed and nondepressed mothers: Tests of an interpersonal impairment hypothesis. Journal of Consulting and Clinical Psychology. 2001; 69:284-294. [PubMed: 11393605]

Hammen C, Brennan PA. Interpersonal dysfunction in depressed women: Impairments independent of depressive symptoms. Journal of Affective Disorders. 2002; 72:145-156. [PubMed: 12200205]

Hammen C, Brennan PA, Le Brocque R. Youth depression and early childrearing: Stress generation and intergenerational transmission of depression. Journal of Consulting and Clinical Psychology. 2011; 79:353-363. [PubMed: 21517152]

Hammen C, Davila J, Brown G, Ellicott A, Gitlin M. Psychiatric history and stress: Predictors of severity of unipolar depression. Journal of Abnormal Psychology. 1992; 101:45-52. [PubMed: 1537972]

Hammen C, Adrian C, Gordon D, Burge D, Jaenicke C, Hiroto D. Children of depressed mothers: Maternal strain and symptom predictors of dysfunction. Journal of Abnormal Psychology. 1987; 96:190-198. [PubMed: 3680756]

Hammen C, Mayol A, DeMayo R, Marks T. Initial symptom levels and the life-event-depression relationship. Journal of Abnormal Psychology. 1986; 95:114-122. [PubMed: 3711434]

Hankin BL, Abramson LY, Moffitt TE, Silva PA, McGee R, Angell KE. Development of depression from preadolescence to young adulthood: Emerging gender differences in a 10-year longitudinal study. Journal of Abnormal Psychology. 1998; 107:128-140. [PubMed: 9505045]

Hankin BL, Kassel JD, Abela JRZ. Adult attachment dimensions and specificity of emotional distress symptoms: Prospective investigations of cognitive risk and interpersonal stress generation as mediating mechanisms. Personality and Social Psychology Bulletin. 2005; 31:136-151. [PubMed: 15574668]

Hankin BL, Mermelstein R, Roesch L. Sex differences in adolescent depression: Stress exposure and reactivity models. Child Development. 2007; 78:279-295. [PubMed: 17328705]

Hankin BL, Stone L, Wright PA. Co-rumination, interpersonal stress generation, and internalizing symptoms: Accumulating effects and transactional influences in a multi-wave study of adolescents. Development and Psychopathology. 2010; 22:217-235. [PubMed: 20102657]

Harkness KL, Lumley MN, Truss AE. Stress generation in adolescent depression: The moderating role of child abuse and neglect. Journal of Abnormal Child Psychology. 2008; 36:421-432. [PubMed: 18092192]

Harkness KL, Luther J. Clinical riskfactorsforthegenerationoflifeevents in majordepression. Journal of Abnormal Psychology. 2001; 110:564-572. [PubMed: 11727946]

Harkness KL, Monroe SM, Simons AD, Thase M. The generation of life events in recurrent and nonrecurrent depression. Psychological Medicine. 1999:135-144. [PubMed: 10077302]

Harkness KL, Stewart JG. Symptom specificity and the prospective generation of life events in adolescence. Journal of Abnormal Psychology. 2009; 118:278-287. [PubMed: 19413403] 
Hoffman L, Stawski RS. Persons as contexts: Evaluating between-person and within-person effects in longitudinal analysis. Research in Human Development. 2009; 6:97-120.

Hollingshead, AB. Four factor index of social status. Department of Sociology, Yale University; New Haven, Connecticut: 1975. Unpublished manuscript

Holsboer F. The corticosteroid receptor hypothesis of depression. Neuropsychopharmacology. 2000; 23:477-501. [PubMed: 11027914]

Jacobson NS, Martell CR, Dimidjian S. Behavioral activation treatment for depression: Returning to contextual roots. Clinical Psychology: Science and Practice. 2001; 8:255-270.

Johnson DP, Whisman MA, Corley RP, Hewitt JK, Rhee SH. Association between depressive symptoms and negative dependent life events from late childhood to adolescence. Journal of Abnormal Child Psychology. 2012; 40:1385-1400. [PubMed: 22592931]

Joiner TE, Wingate LR, Gencoz T, Gencoz F. Stress generation in depression: Three studies on its resilience, possible mechanism, and symptom specificity. Journal of Social and Clinical Psychology. 2005; 24:236-253.

Kaufman J, Birmaher B, Brent D, Rao U, Flynn C, Moreci P, Williamson D, Ryan D. Schedule for Affective Disorders and Schizophrenia for School-Age children - Present and Lifetime version (K-SADS-PL): Initial reliability and validity data. Journal of the American Academy of Child and Adolescent Psychiatry. 1997; 36:980-988. [PubMed: 9204677]

Keller MB, Lavori PW, Friedman B, Nielsen E, Endicott J, McDonalid-Scott P, Andreasen NC. The longitudinal interval follow-up evaluation. Archives of General Psychiatry. 1987; 44:540-548. [PubMed: 3579500]

Keller MB, Lavori PW, Mueller TI, Endicott J, Coryell W, Hirschfeld RMA, Shea T. Time to recovery, chronicity, and levels of psychopathology in major depression: A 5-year prospective follow-up of 431 subjects. Archives of General Psychiatry. 1992; 49:809-816. [PubMed: 1417434]

Kendler KS, Karkowski LM, Prescott CA. Causal relationship between stressful life events and the onset of major depression. American Journal of Psychiatry. 1999; 156:837-841. [PubMed: 10360120]

Kercher AJ, Rapee RM, Schniering CA. Neuroticism, life events and negative thoughts in the development of depression in adolescent girls. Journal of Abnormal Child Psychology. 2009; 37:903-915. [PubMed: 19437113]

Kessler RC, Magee WJ. Childhood adversities and adult depression: Basic patterns of association in a United States national survey. Psychological Medicine. 1993; 23:679-690. [PubMed: 8234575]

Kim KJ, Conger RD, Elder GH, Lorenz FO. Reciprocal influences between stressful life events and adolescent internalizing and externalizing problems. Child Development. 2003; 74:127-143. [PubMed: 12625440]

Kirschbaum C, Pirke KM, Hellhammer DH. The Trier Social Stress Test: A tool for investigating psychobiological stress responses in a laboratory setting. Neuropsychology. 1993; 28:76-81.

Lange C, Zschucke E, Ising M, Uhr M, Bermpohl F, Adli M. Evidence for a normal HPA axis response to psychosocial stress in patients remitted from depression. Psychoneuroendocrinology. 2013; 38:2729-2736. [PubMed: 23931983]

Langrock AM, Compas BE, Keller G, Merchant MJ, Copeland ME. Coping with the stress of parental depression: Parents' reports of children's coping, emotional, and behavioral problems. Journal of Clinical Child and Adolescent Psychology. 2002; 31:312-324. [PubMed: 12149969]

Lopez-Duran NL, Kovacs M, George CJ. Hypothalamic-pituitary-adrenal axis dysregulation in depressed children and adolescents: A meta-analysis. Psychoneuroendocrinology. 2009; 34:12721283. [PubMed: 19406581]

Maciejewski PK, Prigerson HG, Mazure CM. Self-efficacy as a mediator between stressful life events and depressive symptoms: Differences based on history of prior depression. British Journal of Psychiatry. 2000; 176:373-378. [PubMed: 10827887]

McEwen BS. Protective and damaging effects of stress mediators. New England Journal of Medicine. 1998; 338:171-179. [PubMed: 9428819] 
Monroe SM, Harkness KL. Life stress, the "kindling" hypothesis, and the recurrence of depression: Considerations from a life stress perspective. Psychological Review. 2005; 112:417-445. [PubMed: 15783292]

Monroe SM, Harkness KL. Recurrence in major depression: A conceptual analysis. Psychological Review. 2011; 118:655. [PubMed: 21895384]

Morris MC, Ciesla JA, Garber J. A prospective study of stress autonomy versus stress sensitization in adolescents at varied risk for depression. Journal of Abnormal Psychology. 2010; 119:341-354. [PubMed: 20455607]

Morris MC, Rao U. Cortisol response to psychosocial stress during a depressive episode and remission. Stress. 2014; 17:51-58. [PubMed: 24144001]

Morris MC, Rao U, Garber J. Cortisol responses to psychosocial stress predict depression trajectories: Social-evaluative threat and prior depressive episodes as moderators. Journal of Affective Disorders. 2012; 143:223-230. [PubMed: 22858210]

Morris MC, Rao U, Wang L, Garber J. Cortisol reactivity to experimentally manipulated psychosocial stress in young adults at varied risk for depression. Depression and Anxiety. 2014; 31:44-52. [PubMed: 23606237]

Oitzl MS, Champagne DL, van der Veen R, de Kloet ER. Brain development under stress: Hypotheses of glucocorticoid actions revisited. Neuroscience \& Biobehavioral Reviews. 2010; 34:853-866. [PubMed: 19631685]

Patton GC, Coffey C, Posterino M, Carlin JB, Bowes G. Life events and early onset depression: Cause or consequence? Psychological Medicine. 2003; 33:1203-1210. [PubMed: 14580075]

Pettit JW, Lewinsohn PM, Seeley JR, Roberts RE, Yaroslavsky I. Developmental relations between depressive symptoms, minor hassles, and major events from adolescence through age 30 years. Journal of Abnormal Psychology. 2010; 119:811-824. [PubMed: 21090879]

Potthoff JG, Holahan CJ, Joiner TE. Reassurance seeking, stress generation, and depressive symptoms: An integrative model. Journal of Personality and Social Psychology. 1995; 68:664-670. [PubMed: 7738769]

Prinstein MJ. Moderators of peer contagion: A longitudinal examination of depression socialization between adolescents and their best friends. Journal of Clinical Child and Adolescent Psychology. 2007; 36:159-170. [PubMed: 17484689]

Pruessner JC, Kirschbaum C, Meinlschmid G, Hellhammer DH. Two formulas for computation of the area under the curve represent measures of total hormone concentration versus time-dependent change. Psychoneuroendocrinology. 2003; 28:916-931. [PubMed: 12892658]

Raison CL, Miller AH. When not enough is too much: The role of insufficient glucocorticoid signaling in the pathophysiology of stress-related disorders. American Journal of Psychiatry. 2003; 160:1554-1565. [PubMed: 12944327]

Rao U, Hammen C, Ortiz LR, Chen LA, Poland RE. Effects of early and recent adverse experiences on adrenal response to psychosocial stress in depressed adolescents. Biological Psychiatry. 2008; 64:521-526. [PubMed: 18597740]

Raudenbush, SW.; Bryk, AS.; Congdon, R. HLM 6 for Windows. Scientific Software International, Inc; Lincolnwood, IL: 2004.

Ribeiro S, Tandon R, Grunhaus L, Greden J. The DST as a predictor of outcome in depression: A meta-analysis. American Journal of Psychiatry. 1993; 150:1618-1629. [PubMed: 8214170]

Rudolph KD, Flynn M, Abaied JL, Groot A, Thompson R. Why is past depression the best predictor of future depression? Stress generation as a mechanism of depression continuity in girls. Journal of Clinical Child and Adolescent Psychology. 2009; 38:473-485. [PubMed: 20183635]

Rudolph KD, Hammen C. Age and gender as determinants of stress exposure, generation, and reactions in youngsters: A transactional perspective. Child Development. 1999; 70:660-677. [PubMed: 10368914]

Rudolph KD, Hammen C, Burge D, Lindberg N, Herzberg D, Daley SE. Toward an interpersonal lifestress model of depression: The developmental context of stress generation. Development \& Psychopathology. 2000; 12:215-234. [PubMed: 10847625] 
Safford SM, Alloy LB, Abramson LY, Crossfield AG. Negative cognitive style as a predictor of negative life events in depression-prone individuals: A test of the stress generation hypothesis. Journal of Affective Disorders. 2007; 99:147-154. [PubMed: 17030064]

Sandberg S, McGuinness D, Hillary C, Rutter M. Independence of childhood life events and chronic adversities: A comparison of two patient groups and controls. Journal of the American Academy of Child and Adolescent Psychiatry. 1998; 37:728-735. [PubMed: 9666628]

Sawyer, MG.; Arney, FM.; Baghurst, PA.; Clark, JJ.; Graetz, BW.; Kosky, RJ.; Nurcombe, B.; Patton, GC.; Prior, MR.; Raphael, B.; Rey, J.; Whaites, LC.; Zubrick, SR. The mental health of young people in Australia, Mental Health and Special Programs Branch. Commonwealth Department of Health; Canberra: 2000.

Segal ZV, Williams JM, Teasdale JD, Gemar M. A cognitive science perspective on kindling and episode sensitization in recurrent affective disorder. Psychological Medicine. 1996; 26:371-380. [PubMed: 8685293]

Shiffman S, Stone AA, Hufford MR. Ecological Momentary Assessment. Annual Review of Clinical Psychology. 2008; 4:1-32.

Shih JH. Sex differences in stress generation: An examination of sociotropy/autonomy, stress, and depressive symptoms. Personality and Social Psychology Bulletin. 2006; 32:434-446. [PubMed: 16513797]

Shih JH, Abela JRZ, Starrs C. Cognitive and interpersonal predictors of stress generation in children of affectively ill parents. Journal of Abnormal Child Psychology. 2009; 37:195-208. [PubMed: 18802680]

Singer, JD.; Willett, JB. Applied longitudinal data analysis: Modeling change and event occurrence. Oxford University Press; New York, NY: 2003.

Solomon DA, Keller MB, Leon AC, Mueller TI, Lavori PW, Shea MT, Endicott J. Multiple recurrences of major depressive disorder. American Journal of Psychiatry. 2000; 157:229-233. [PubMed: 10671391]

Sorenson SB, Rutter CM, Aneshensel CS. Depression in the community: An investigation into age of onset. Journal of Consulting and Clinical Psychology. 1991; 59:541-546. [PubMed: 1918558]

Spitzer, RL.; Williams, JBW.; Gibbon, M.; First, MB. User's guide for the Structured Clinical Interview for DSM-III-R. American Psychiatric Press; Washington, DC: 1990.

Trestman RL, Coccaro EF, Bernstein D, Lawrence T, Gabriel SM, Horvath TB, Siever LJ. Cortisol responses to mental arithmetic in acute and remitted depression. Biological Psychiatry. 1991; 29:1051-1054. [PubMed: 2065138]

Vreeburg SA, Hoogendijk WJG, van Pelt J, DeRink RH, Verhagen JCM, van Dyck R, Smit JH, Zitman FG, Penninx BWJH. Major depressive disorder and hypothalamic-pituitary-adrenal axis activity: Results from a large cohort study. Archives of General Psychiatry. 2009; 66:617-626. [PubMed: 19487626]

Vrshek-Schallhorn S, Doane LD, Mineka S, Zinbarg RE, Craske MG, Adam EK. The cortisol awakening response predicts major depression: Predictive stability over a 4-year follow-up and effect of depression history. Psychological Medicine. 2013; 43:483-493. [PubMed: 22652338] 


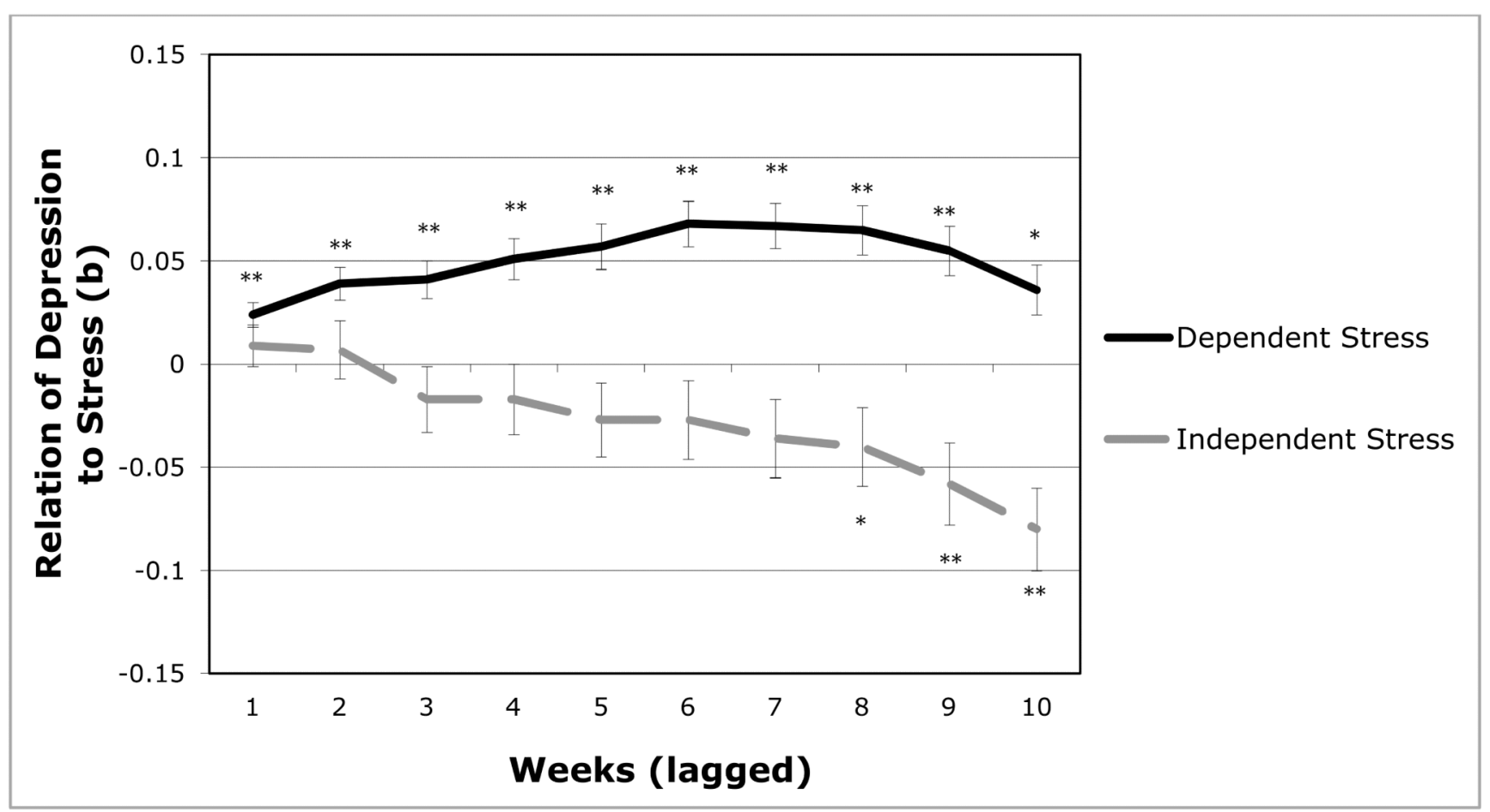

Figure 1.

Lagged effects of depression symptom rating (DSR) scores on total stress levels (dependent, independent) in adolescents (Study 1).DSRs are lagged $n$ weeks behind stress levels at time $t$. Unstandardized beta coefficients represent the strength of relations between DSR scores and stress levels and error bars represent standard errors.

$* p<.01 ; * * p<.001$ 


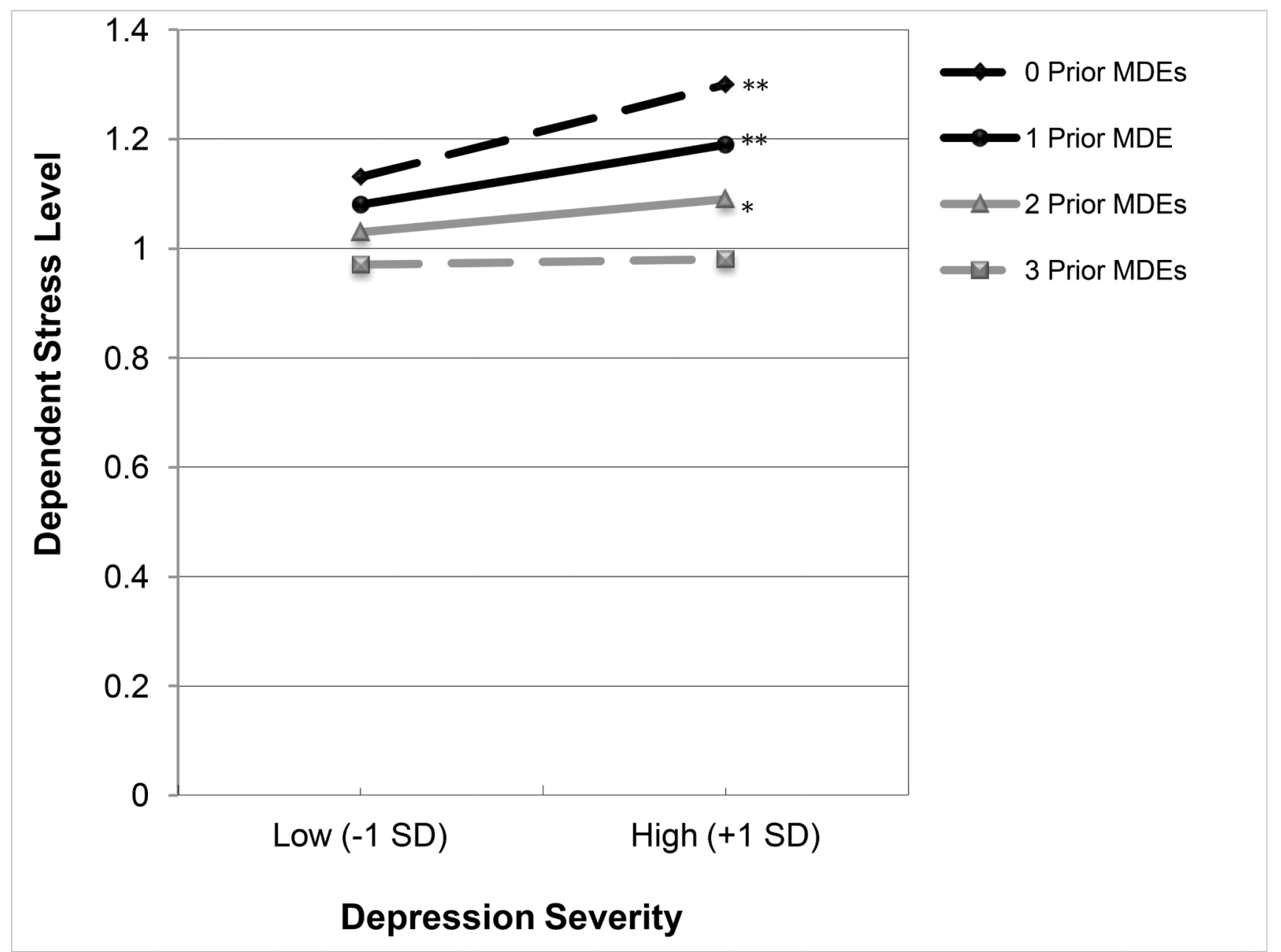

Figure 2.

Interaction of depression symptom ratings (DSRs) (lagged 6 weeks) and previous MDEs predicting dependent stress levels in adolescents (Study 1).

$* p<.05 ; * * p<.001$ 


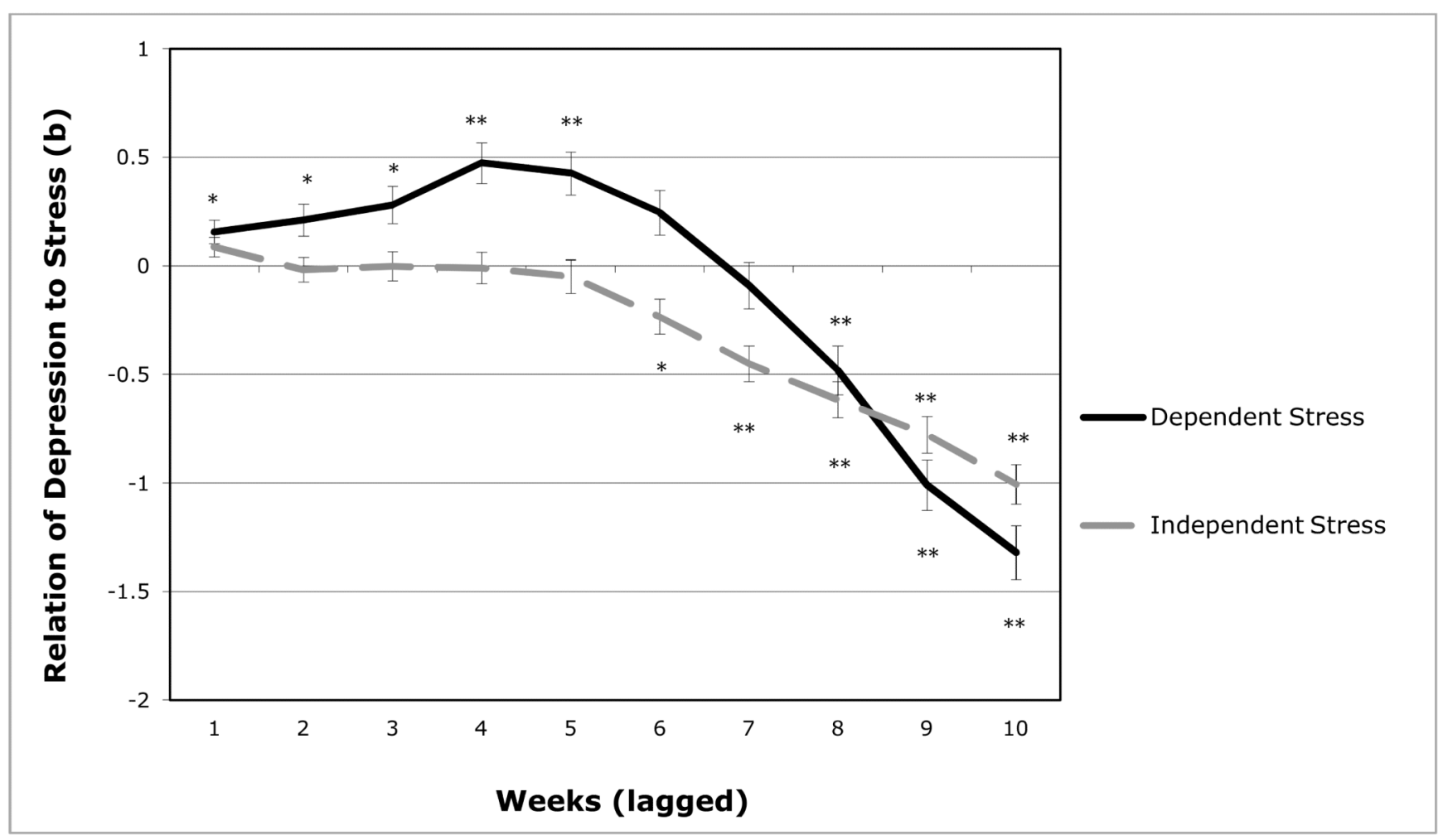

Figure 3.

Lagged effects of depression symptom ratings (DSR) on total stress levels (dependent, independent) in young adults (Study 2). DSRs are lagged $n$ weeks behind dependent stress levels at Time $t$. Unstandardized beta coefficients represent the strength of relations between DSR scores and stress levels and error bars represent standard errors.

$* p<.01 ; * * p<.0001$ 


\section{Higher Cortisol Response}
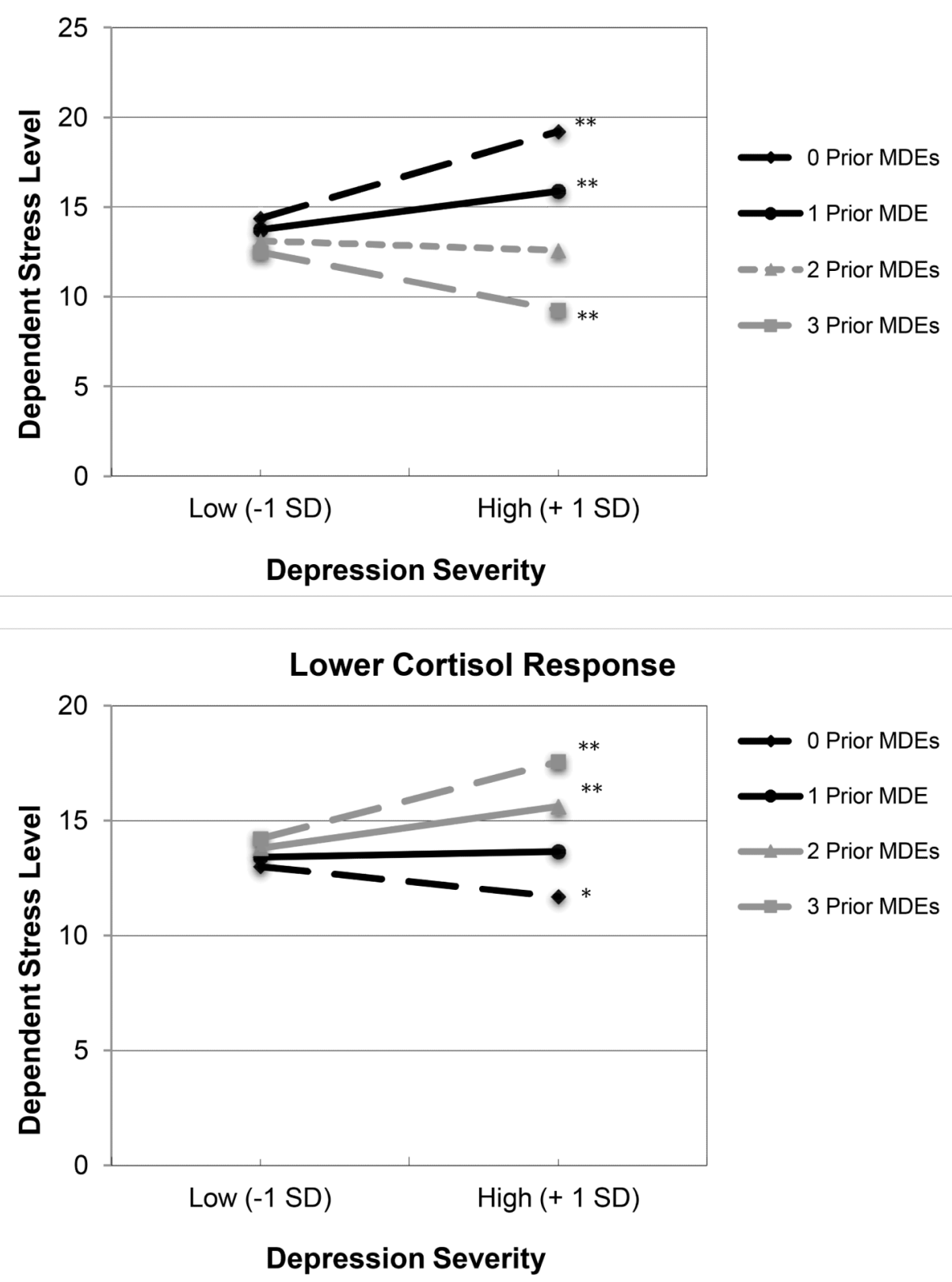

Figure 4.

Interaction of cortisol responses (AUCg), prior MDEs, and lagged DSRs predicting dependent stress levels in young adults (Study 2 ). ${ }^{*} p<.05 ; * * p<.001$ 


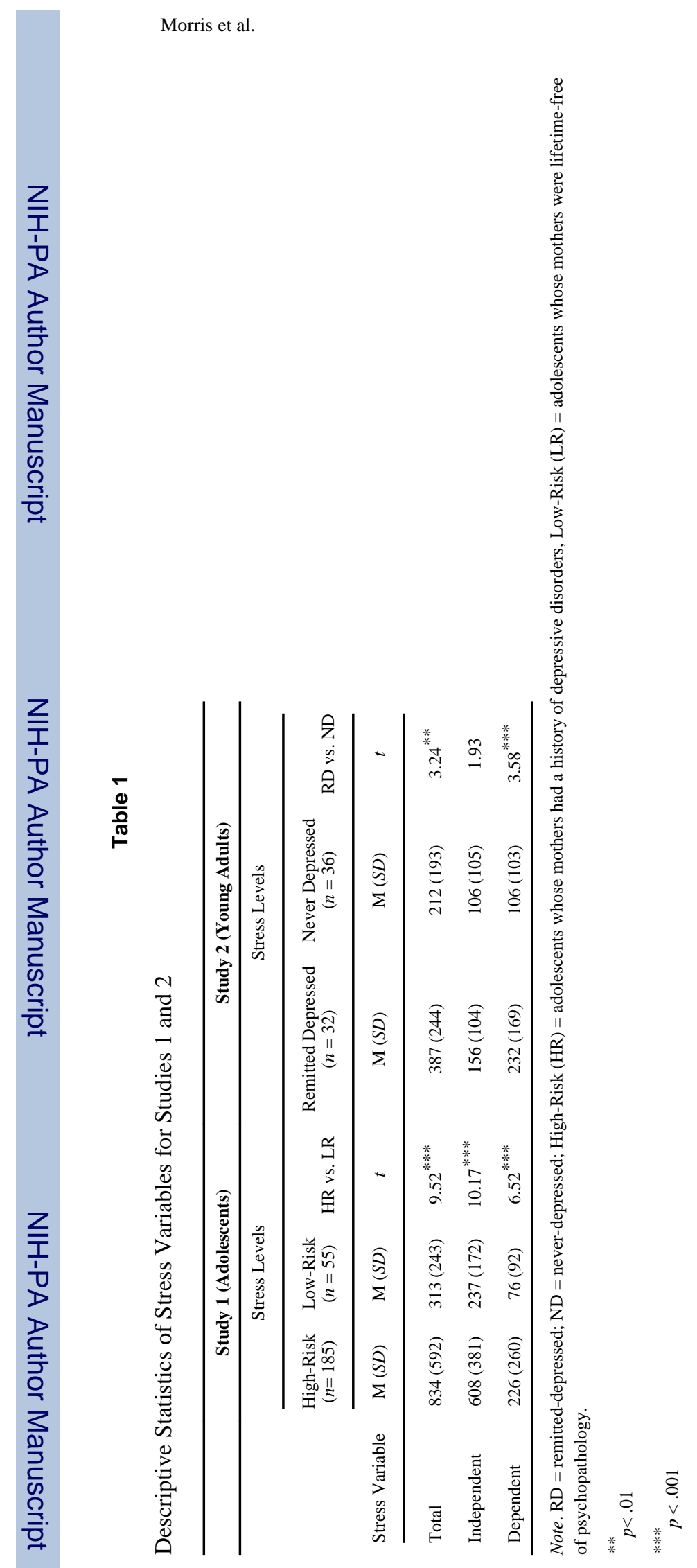

Dev Psychopathol. Author manuscript; available in PMC 2015 November 01. 


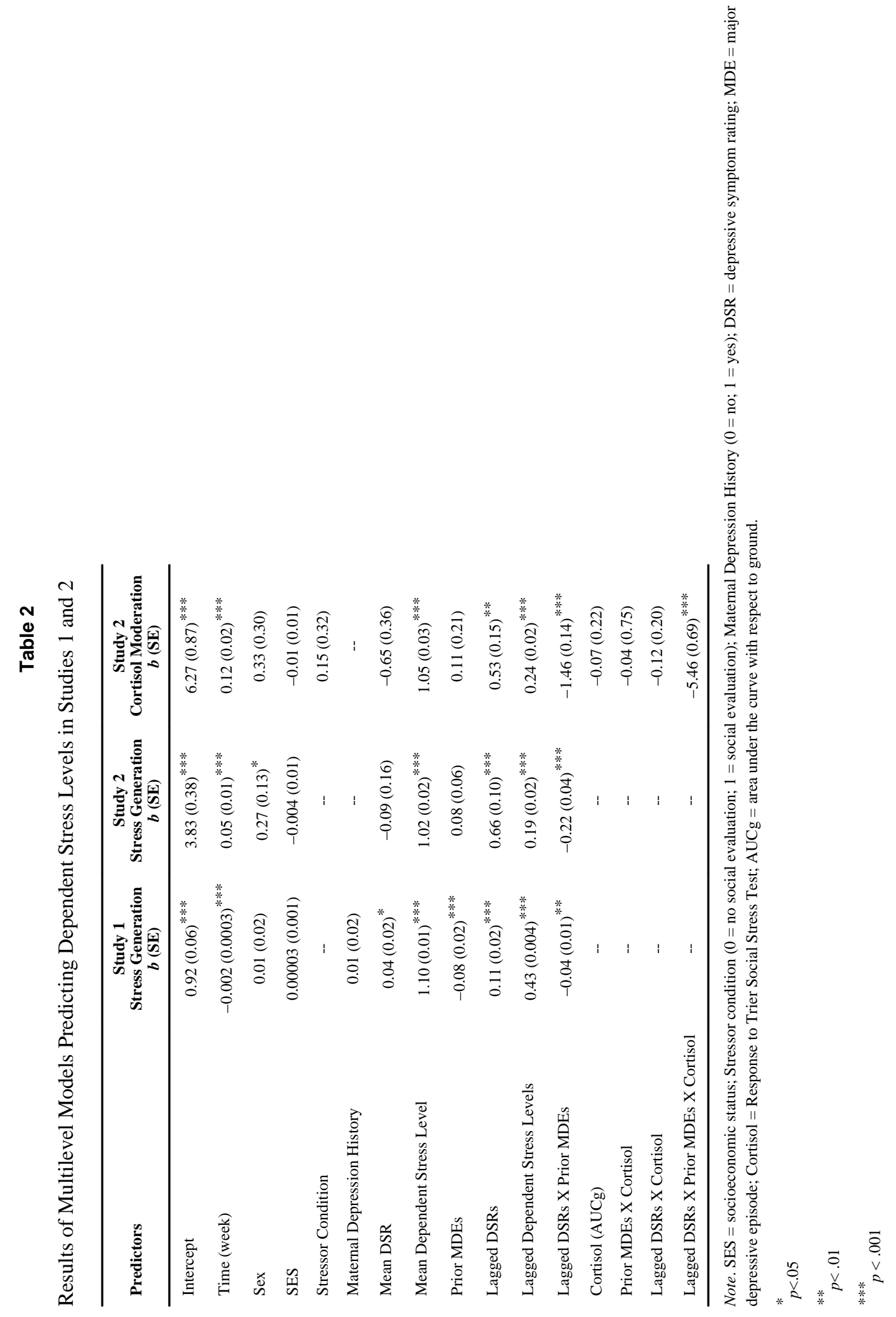

